La accesibilidad a los medios de comunicación audiovisuales ha de DOSSIER $\cdot 115-134$ favorecer la aproximación y la familiarización de las personas sordas con la sociedad del conocimiento y de la información, así como con lo que constituyen sus instrumentos, nuevas tecnologias de inmensas potencialidades, que abren profundos horizontes a las relaciones de comunicación del hombre con el hombre, así como del hombre con el mundo en el que vive. Al tiempo que dotan al ser humano de una enorme -y siempre creciente- capacidad para ampliar las vías de acceso a la información y a la cultura, a fin de que dichas personas sordas consigan superar su proverbial desarraigo, alcancen a mejorar su, hoy por hoy, poco envidiable calidad de vida, y logren así participar, de una manera activa y plena, como ciudadanos, en la vida política, al igual que en la toma y en la ejecución de las decisiones que les puedan concernir, tanto en el ámbito del Estado al que pertenecen, como en el de las distintas comunidades en las que pudieran encontrarse integrados.

PALABRAS CLAVE: Accesibilidad, Derechos a la información y a la comunicación, Sordera, Lenguas de señas, Subtitulación, Audio descripción.

\title{
Construcción jurídica del derecho a una televisión accesible
}

José Gabriel Storch de Gracia y Asensio Universidad Complutense de Madrid
Accessibility to audiovisual media must favour the approach and familiarization of deaf people with the knowledge and information society, as well as with their instruments, new technologies of immense potentialities which open new horizons to the communication relationships between the human beings and between the man and his surrounding world. At the same time, they offer the human being an enormous -and always increasing- capacity to improve the ways to access the information and culture and can be used by the deaf people to overcome their traditional uprooting, improve their present poor quality of life and be able to participate, in a full and active way, as citizens, in the political life and in the making process and implementation of those decisions that affect them, in the State and in the different communities where they are integrated.

KEYWORDS: Accessibility, Rights to the information and communication, Deafness, Sign languages, Subtitulation, Audio description. 


\section{EL CONTEXTO SOCIAL Y CONSTITUCIONAL}

En un sentido genérico o abstracto, y es afirmación generalizada que raya casi en grosero tópico, está fuera de toda duda que todos y cada uno de los ciudadanos tienen derecho a acceder a la información en general.

En efecto, según el tenor del art. 20.I.d) de la Constitución, "... se reconocen y protegen los derechos... a comunicar o recibir libremente información veraz por medio de cualquier medio de difusión...», añadiendo los siguientes apartados del mismo artículo que «... el ejercicio de estos derechos no puede restringirse mediante ningün tipo de censura previa...», que «... la ley regulará la organización y control parlamentario de los medios de comunicación social dependientes del Estado o de cualquier ente público y garantizará el acceso a dichos medios de los grupos sociales y politicos significativos, respetando el pluralismo de la sociedad y de las diversas lenguas de España ...» y que «... estas libertades tienen su limite en el respeto de los derechos reconocidos en este Título, en los preceptos de las leyes que los desarrollen $y$, especialmente, en el derecho al honor, a la intimidad, a la propia imagen y a la protección de la juventud y de la infancia... ».

Pero resulta que, por vía de hecho, las personas sordas tienen dificultado o impedido —así, pues, limitado o menoscabado, en mayor o menor medida, según la intensidad de la sordera - su derecho a recibir información, cuando ésta se instrumenta mediante el sonido: Conversación oral (en todos los ámbitos, ya sea

I Para más detalle sobre el derecho a la información y su aplicación al caso de las personas sordas, vid. José-Gabriel Storch de Gracia y Asensio: «Acerca del derecho de las personas sordas a una televisión accesible», en Revista Jurídica La Ley, 1998, vol. 4, pp. I430 y ss. y José-Gabriel Storch de Gracia y Asensio: «Derecho a la información y discapacidad (una reflexión acerca del lenguaje de los sordos)», en Revista General de Información y Documentación (Madrid: 2006), vol. I6, $\mathrm{n}^{\circ}$ I, págs. 75-103, passim.

familiar, educativo, profesional, etc.), Radio y Televisión. De manera que si no se hacen accesibles a aquéllas los instrumentos de acceso a la información, se incumple el principio constitucional de la generalidad o universalidad de los derechos fundamentales, especialmente de los que son ejercitables a través del lenguaje.

En su reivindicación por la accesibilidad a la información y a la comunicación, late, en esencia, la legítima aspiración de las personas sordas a la mejora de su calidad de vida o, dicho en términos constitucionales, a ejercer el derecho al «libre desarrollo de la personalidad $»^{2}$, mediante una adecuada y normal integración de aquéllas en la sociedad, por eliminación de la única barrera que, efectivamente, la impide o dificulta: la de comunicación. Téngase en cuenta que los sordos «oímos por los ojos» (por medio de las lecturas gestual, labial y textual, es decir, en todo caso, a través de signos gráficos e imágenes).

Prescindiendo aquí y por ahora de las cuestiones referentes a la divulgación de las lenguas de señas, vamos a centrar el presente trabajo en el estudio de una puntual cuestión jurídica: habida cuenta de las limitaciones de las personas sordas para acceder rápida e inmediatamente a los medios de comunicación social (la Radio está, obviamente y dado el estado actual de la Técnica, descartada y la Prensa no tiene ese carácter de inmediatez informativa, quedando, pues, la Televisión, siempre que ésta emita sus programas con apoyo de las imágenes que, adecuadamente, permitan las antes citadas lecturas gestual, labial y/o textual), ¿tienen aquéllas derecho al acceso expedito a los programas televisivos, ya por la subtitulación de los mismos, ya por su emisión por medio de lengua gestual? Y, en caso afirmativo, ¿está suficientemente protegi-

2 Cfr. art. Io.I CE. 
do - por exigible- este derecho en el estado actual de la legislación española?

Si consideramos, como establecen taxativamente los arts. I9 de la Declaración Universal de Derechos Humanos y ro.r del Convenio Europeo de Derechos Humanos, que el derecho fundamental de libre expresión comprende, también, el derecho a recibir información ${ }^{3}$, la falta de accesibilidad a la información por parte de las personas sordas ${ }^{4}$, niega radicalmente el ejercicio por las mismas del mencionado derecho fundamental, calificado, como se ha dicho

3 Cfr. el art. Ig de la Declaración Universal de Derechos Humanos, de ro de diciembre de I948, directamente aplicable en España, de conformidad con lo dispuesto en el art. ro.2 de nuestra Constitución. Dicha norma internacional dice que:

«... Todo individuo tiene derecho a la libertad de opinión y de expresión; este derecho incluye el de no ser molestado a causa de sus opiniones, el de investigar y recibir informaciones y opiniones, y el de difundirlas, sin limitación de fronteras, por cualquier medio de expresión...».

Tengamos en cuenta también el Pacto Internacional de Derechos Civiles y Políticos, que se refiere asimismo a los derechos mencionados. Así, en su art. 26, tras reconocer la igualdad de todas las personas ante la ley, y el derecho, sin discriminación, a igual protección de la ley, determina que ésta prohibirá toda discriminación por una serie de motivos que se enumeran, entre los cuales figura el idioma. Además, en su art. I9 contempla el derecho a la libertad de expresión, especificando que el mismo comprende la libertad de buscar, recibir y difundir informaciones e ideas de toda índole, ya sea oralmente, por escrito o en forma impresa o artística, o por cualquier otro procedimiento.

Cfr., igualmente, el art. io del Convenio Europeo de Derechos Humanos, signado en Roma el I4 de noviembre de I.950, firmado y ratificado por España, respectivamente, el 24 de noviembre de 1977 y el 4 de octubre de r.979. Dice, literalmente, lo siguiente:

«...Art. Io. I. Toda persona tiene derecho a la libertad de expresión. Este derecho comprende la libertad de opinión y la libertad de recibir o de comunicar informaciones o ideas sin que pueda haber injerencia de autoridades públicas y sin consideración de fronteras. El presente artículo no impide que los Estados sometan a las empresas de radiodifusión, de cinematografía o de televisión a un régimen de autorización previa.2. El ejercicio de estas libertades, que entrañan deberes y responsabilidades, podrá ser sometido a ciertas formalidades, condiciones, restricciones o sanciones con harta reiteración, de esencial para la constitución de una sociedad libre y democrática.

Y no sólo eso, con ser grave, sino que, también, se incumplen los fines expresados en el art. 4 de la Ley $4 /$ r980, de ro de enero, Reguladora del Estatuto de la Radio y la Televisión, y demás normas concordantes, por citar un ejemplo. A saber: además de desconocer, en los términos dichos, el derecho a la libertad de expresión, se vulneran aquellos otros derechos fundamentales que utilizan el lenguaje como vehículo de

previstas por la ley, que constituyan medidas necesarias, en una sociedad democrática, para la seguridad nacional, la integridad territorial o la seguridad pública, la defensa del orden y la prevención del delito, la protección de la salud o de la moral, la protección de la reputación o de los derechos ajenos, para impedir la divulgación de informaciones confidenciales o para garantizar la autoridad y la imparcialidad del poder judicial...».

Para una perspectiva internacional y constitucional, vid. Manuel Aznar López, «La lengua de señas en el contexto de los derechos de las personas con discapacidad: Los textos internacionales y la Constitución española», y desde el Derecho comparado, vid. José Gabriel Storch de Gracia y Asensio, «Derecho comparado: Las lenguas de señas en los textos extranjeros (Recopilación legislativa)», ambos en José Gabriel Storch de Gracia y Asensio (coord.) \& alii, Estatuto jurídico de las lenguas de señas en el Derecho español (Aproximaciones), Col. Por más señas, Ed. Universitaria Ramón Areces, Madrid 2005, pp. 275-294 y 295-4I4, respectivamente.

4 Cuyo número, en España, supera el millón de afectados. Si bien es cierto que, aún, no hay fuentes o estadísticas absolutamente fiables que determinen con exactitud dicho número, el dato se puede obtener, indiciariamente, de las siguientes fuentes: CNSE, Las personas sordas en España, Situación actual, necesidades y demandas, Madrid s/f (aunque nos consta que fue editado en 1997), pág.II, donde, citando un censo del Instituto Nacional de Servicios Sociales (INSERSO) del año I992, se tabula en 930.I25 personas. La Diputada del Congreso de los Diputados Doña Carmen Marón Beltrán expone que el número puede estar en torno a un millón de personas sordas (Diario de Sesiones del Congreso de los Diputados del I6 de diciembre de 1997). Una Encuesta Nacional sobre Discapacidades realizada por el INE y la Fundación ONCE se puede ver en la p. web http:// www.ine.es/prodyser/pubweb/discapa/discapamenu.htm. 
articulación (derecho a la educación, derecho a la defensa jurídica -especialmente en aquellos procesos donde predominan los principios de oralidad e inmediatez, cada vez más numerosos, a la luz de las más recientes reformas procesales, derecho al acceso a la cultura, etc. $)^{5}$, se ignora el pluralismo informativo por desconocimiento de la especificidad social, cultural y lingüística de las personas sordas ${ }^{6}$, y se discrimina a éstas, despreciándose, así, el necesario respeto de los valores de igualdad recogidos en el artículo I4 de la Constitución?.

5 Para una exposición sucinta de los derechos fundamentales afectados, vid. la Proposición no de Ley para el reconocimiento oficial de la Lengua de Signos Española, propuesta por el Grupo Parlamentario de Izquierda Unida (Boletín Oficial de las Cortes del 4 de noviembre de 1997, Congreso de los Diputados, pp. 9 y ss, sub epígrafe $\mathrm{n}^{\circ} \mathrm{I} 6 \mathrm{I} / 000708$ ) y que fue aprobada por unanimidad, con la enmienda transaccional que allí se recoge, por la Comisión de Política Social del Congreso de los Diputados (Diario de Sesiones del Congreso de los Diputados del I6 de diciembre de 1997).

6 La instrumentación espacial-visual de su comunicación ha conformado la existencia de una comunidad virtual, con sus diferencias culturales, sociales y lingüísticas, que ha venido en denominarse «comunidad sorda» y que la situación de marginación social en que se hallan sus miembros provoca que sea configurada como un auténtico gueto. Vid., al respecto, entre otros, los siguientes trabajos: María del Pilar Fernández Viader, La comunicación de los niños sordos (Interacción comunicativa padres-hijos), Ed. CNSE, Barcelona 1996; Félix-Jesús Pinedo Peydró, El sordo y su mundo, Ed. CNSE, Valladolid I981; Íd., Una voz para un silencio, Ed. cNse, Madrid 1989.

7 Nótese la sangrante desigualdad que puede producirse, v.gr., en materia de Protección Civil: en situaciones de alarma, catástrofe o calamidad públicas, el art. $4.6^{\circ}$ de la Ley 2/r.985, de 2I de enero, de Protección Civil, establece que «... En las situaciones de emergencia contempladas en esta Ley, los medios de comunicación social vendrán obligados a colaborar con las autoridades competentes respecto a la divulgación de informaciones dirigidas a la población y relacionadas con dichas situaciones...", añadiendo el art. 22 de la Ley 4/r.980, Reguladora del Estatuto del Ente Público de Radio y Televisión, que «...El Gobierno podrá hacer que se programen y difundan cuantas declaraciones o comunicaciones oficiales de interés público estime necesarias, con indicación de su origen. Por razones de urgencia, apreciadas por el propio Gobierno, estos comunicados
Valores que son explícitamente recogidos en diversos Acuerdos de Organismos internacionales y que, aún, no han sido objeto de aplicación generalizada en la práctica, legislativa y reglamentaria, española, aunque vamos por el buen camino ${ }^{8}$.

El respeto a la dignidad, a la igualdad y a la libertad humanas se caracteriza aquí, remarcadamente si cabe, por la concurrencia de una comunidad virtual de personas con discapacidad, las sordas, que usan, originaria o derivativamente, las lenguas gestuales. Es sabido que, históricamente, dicha categoría de personas ha sido objeto de dis-

$y$ declaraciones tendrán efecto inmediato...», y el art. I6 de la Ley 190/r.988, de ro de mayo, sobre Televisión Privada, que «... Las sociedades concesionarias estarán obligadas a difundir, gratuitamente y con indicación de su origen, los comunicados y declaraciones que en cualquier momento y en razón de su interés público, el Gobierno estime necesarios...» (Y en igual o parecido sentido se manifiesta la legislación autonómica en tales materias de Protección Civil y Televisión). Este principio de inmediatez informativa es absolutamente necesario para la adecuada eficacia de los servicios de Protección Civil, pero que, por la falta de accesibilidad a los medios de comunicación por parte de las personas sordas, no surte tales efectos inmediatos respecto de éstas, no quedándoles otra suerte que la resignación ante lo inevitable o la esperanza de que otra persona -oyente- les informe de las situaciones de alarma.

${ }^{8}$ Las Normas Uniformes sobre la Igualdad de Oportunidades de las Personas con Discapacidad, aprobadas por la Asamblea General de las Naciones Unidas, mediante la Resolución 48/96, del 20 de diciembre de r993, cuyo art. 5.b) proclama, explícitamente, que «...Los Estados deben elaborar estrategias para que los servicios de información y de documentación sean accesibles a los diferentes grupos de personas con discapacidad. A fin de proporcionar acceso a la información $y$ documentación escritas a las personas con deficiencias visuales, deben utilizarse el sistema Braille, grabaciones en cinta, tipos de imprenta grandes y otras tecnologías apropiadas. De igual modo, deben utilizarse tecnologias apropiadas para proporcionar acceso a la información oral a las personas con deficiencias auditivas o dificultades de comprensión... Se debe considerar la utilización del lenguaje de señas en la educación de los niños sordos, así como en sus familias y comunidades. También deben prestarse servicios de interpretación del lenguaje de señas para facilitar la comunicación entre las personas sordas y las demás personas... Deben tenerse en cuenta asimismo las necesidades de las personas con otras discapacidades de comunicación... Los Estados deben estimular a los medios de comunicación, en espe- 
criminación. Y en muchos sentidos sigue siéndolo, tanto en las legislaciones como en la práctica cotidiana, especialmente en todo cuanto se refiere al ejercicio de derechos - incluso fundamentales- que usan el lenguaje como medio de articulación o ejercicio: no hay más que pensar, por ejemplo, en los derechos fundamentales al aprendizaje y uso de la lengua castellana (art. 3.I de la Constitución española, en adelante $\mathrm{CE}$ ) o de la cooficial en cada Comunidad Autónoma (art. 3.2 CE), a la libre expresión y al derecho a recibir información (art. $20 \mathrm{CE}$, planteándose, aquí, la cuestión de la

cial a la televisión, a la radio y a los periódicos, para que hagan accesibles sus servicios... Los Estados deben garantizar que los nuevos sistemas de servicios y de datos informatizados que se ofrezcan al público en general sean desde un comienzo accesibles a las personas con discapacidad, o se adapten para hacerlas accesibles a ellas... Debe consultarse a las organizaciones de personas con discapacidad cuando se elaboren medidas encaminadas a proporcionar a esas personas acceso a los servicios de información...».

En nuestro entorno geográfico, la Resolución del Parlamento Europeo sobre las Lenguas de Señas, del I7 de junio de I.988 (en OJ c r87, del 18.07.I.988, págs. 236 y ss.), reconoce el derecho de las personas sordas al aprendizaje y utilización de las lenguas gestuales en sus relaciones con las demás personas, y establece el deber de los Estados miembros de favorecer y extender su uso y aprendizaje, como manifestación cultural de una comunidad específica (la Comunidad Sorda) y como instrumento de integración social de las personas sordas en el resto de la Sociedad. En idéntica dirección integradora, la Comunicación de la Comisión de la Unión Europea sobre la Igualdad de Oportunidades de las Personas con Minusvalía, del 30 de julio de r.996 -que incluye un Proyecto de Resolución del Consejo y de los Representantes de los Gobiernos en la misma línea (COM(96) 406 final, 96/o216 CNS)-, tras exponer, entre otras cosas, la pretensión de la Comisión de «...aprovechar el potencial de la Sociedad de la Información para promover la igualdad de oportunidades, especialmente a través del desarrollo de las Tecnologias de la Información y de las Comunicaciones (TIC), y creará un grupo ad hoc interno para este fin...", propone una Directriz que contiene, a los efectos que nos ocupan, el compromiso de los Estados miembros para «...garantizar un entorno sin barreras ... y desarrollar nuevas tecnologías de comunicaciones, con especial atención a la necesidad de aprovechar positivamente los avances en el campo de las TIC». accesibilidad a los medios de comunicación que utilizan el sonido, o la aplicación a la televisión de las técnicas de la subtitulación textual y de la interpretación gestual), a la defensa (art. 24 CE, máxime cuando se tiende, en las más recientes reformas procesales, a la oralidad de los juicios), a la educación (art. $27 \mathrm{CE}$, planteándose aquí la puntual necesidad de una educación con maestros sólidamente bilingües, donde el uso de las lenguas gestuales pueda combinarse con adecuadas dosis de lectoescritura y de aprendizaje de la lengua oral, todo ello en la medida que lo exijan las necesidades y lo permitan las capacidades comunicativas de los alumnos sordos, si se quiere que se cumpla el mandato constitucional de la adecuación del derecho de educación a la personalidad del formando, en orden a su plena integración social en condiciones de libre desarrollo de la personalidad), al acceso a la cultura, etc 9 .

No en vano dijo el filósofo y lingüista británico, de origen austríaco, Ludwig-Joseph-Johann Wittgenstein que «los limites de mi lenguaje son los limites de mi mundo» ${ }^{\mathrm{I}}$.

Por eso, la comunicación de los sordos - $\mathrm{y}$, por consiguiente, su plena integración social en condiciones de igualdad en dignidad y libertad- está, de hecho, supeditada a su nivel de adquisición del lenguaje a partir de sus propias capacidades y posibilidades relacionales (familiares y sociales) y de sus experiencias educativas. En suma, de sus posibilidades de recibir información de un entorno familiar, educativo y social lo más accesible y amplio posible ${ }^{\mathrm{II}}$.

9 Vid. José Gabriel Storch de Gracia y Asensio, "Acerca del derecho...», en Revista Jurídica La Ley, op. cit., p. I43I.

Io Vid. Ludwig Wittgenstein, «Tractatus logico-philosophicus», trad. cast. de Enrique Tierno Galván, Alianza Ed., Madrid, I973, p. I63.

II Para una visión histórica de la cuestión, vid. Antonio Gascón Ricao y José Gabriel Storch de Gracia y Asensio, Historia de la educación de los sordos en España y su 
En el mundo occidental, los vehículos de expresión y comunicación que más utilizan las personas sordas congénitas o prelocutivas entre 120 sí, con independencia de que en determinados casos puedan usar en su relación con los oyentes el lenguaje hablado, escrito o la lectura labial, lo constituyen dos: el alfabeto manual (que, en rigor, no es propiamente un lenguaje autónomo y propio, sino expresión viso-gestual o notación espacial del alfabeto de la correspondiente lengua oral o, mejor dicho, de sus «gramma» escritos) y la lengua o idioma propio de las personas sordas, conocido en español con los términos de «lengua gestual» o «lengua de señas», por milenaria ignorancia peyorativa «lenguaje mímico», o también, más vulgar y pleonásticamente por mala traducción al español de textos franceses e ingleses, «lengua de signos», cuando lo cierto es que todas las lenguas, desde un punto de vista estructuralista o saussuriano, sólo se componen de «signos» (sonoros, escritos, ideográficos, gestuales, etc.... $)^{\mathrm{I} 2}$.

influencia en Europa y América, Ed. Universitaria Ramón Areces, Col. Por Más Señas, Madrid 2004, y Manuel López Torrijo, La educación de las personas con sordera: La escuela oralista española, Universitat de València, Valencia 2005, passim.

${ }^{12}$ Sobre esta cuestión terminológica y sus consecuencias sociales, vid. José Gabriel Storch de Gracia y Asensio, (1998): El nombre de nuestra lengua, en la p. web http://www.ucm.es/info/civil/bardecom/docs/signa. pdf; Antonio Gascón Ricao (1998-2003): ¿ Señas o signos? Evolución histórica, en la p. web www.ucm.es/info/civil/bardecom/docs/signos.pdf; y Antonio Gascón Ricao y José Gabriel Storch de Gracia y Asensio (2003): Historia de la Lengua de Señas Española: Polémicas, tópicos, mitos y leyendas, en la p. web www.ucm.es/info/civil/herpan/docs/historiar. pdf. Cuestión o debate que la dirección de la Confederación Nacional de Sordos de España (CNSE) ha elevado a categoría dogmática y, por supuesto, logomáquica, hasta el punto de realizar una práctica de expulsiones y amenazas de ostracismo de todo punto inaceptable, orquestada desde una perspectiva irracional de «Despotismo Inilustrado», de absoluto control cultural colectivista e identitario de las personas sordas a partir de un exagerado y patológico «language
En la encuesta sobre Discapacidades, Deficiencias y Estado de Salud (considerando una población de entre 6 y 64 años) del Instituto Nacional de Estadística (año de 1999) ${ }^{\mathrm{r}}$, en el apartado «Oír», se habla de 343.000 personas; de las que 47.000 padecen sordera profunda, 66.000 severa y 230.000 moderada. De ellas, son potencialmente usuarias de las lenguas de señas las del primer grupo, por no poder usar plenamente las lenguas orales. Contrastados estos datos con los publicados por la Consejería de Servicios Sociales de la Comunidad de Madrid en 1998 -según los cuales hay aproximadamente $\mathbf{3} 3.000$ personas con discapacidad auditiva que tienen el «Certificado de minusvalía» por discapacidad superior al $33 \%$ - y con los del censo de electores de la Federación de Sordos de la Comunidad de Madrid (FeSorCam), también de 1998 - por los que hay afiliadas a las asociaciones de sordos pertenecientes a dicha Federación unas 2.500 personas, la casi totalidad señantes-, podemos afirmar que el número total de sordos señantes en España puede rondar entre 35.000 y 50.000 personas (entre un 3,5 y un $5 \%$ del total de sordos censados), de modo que la abrumadora mayoría emplea la lengua oral en su comunicación ${ }^{\mathrm{I}}$.

ownership», configurador de una auténtica «servidumbre de la etnia», que ya denunciara Giovanni Sartori en La sociedad multiétnica, Pluralismo, multiculturalismo y extranjeros, Col. Taurus Pensamiento, Ed. Taurus, Madrid 20oı, pp. IO5-I26 y en Homo videns. La sociedad teledirigida, Col. Taurus Pensamiento, Ed. Taurus, $2^{\mathrm{a}}$ ed. anotada, Madrid 200o, pp. 127 y ss.. Vid. también José Iturmendi Morales, «En torno a la "Comunidad Sorda» como comunidad de aprendizaje y de actitudes de pertenencia y de fidelidad. Una aportación al debate entre comunitaristas y liberales acerca de los derechos, los valores y la Sociedad», en José Gabriel Storch de Gracia y Asensio (coord.) \& alii, Estatuto jurídico..., op. cit., ed. cit., passim.

${ }_{\text {r3 }}$ Cfr. la p. web http://www.ine.es/prodyser/pubweb/ discapa/discapamenu.htm.

${ }_{14}$ Cifras proporcionales que guardan relación con la que se obtiene de las estadísticas médicas, por las que se 
Datos como éstos tienen implicaciones, como el hecho de que la ratio de intérpretes no pueda ser de I para 22I sordos (si aceptáramos estas cifras, publicadas por el Presidente de la CNSE), sino de aproximadamente I para cada 8 a I6 personas sordas señantes. La insuficiencia no ya sólo es cuantitativa, con serlo, sino más bien cualitativa: al proverbial bajo índice de formación que padece la mayoría de los profesores y los intérpretes de lenguas de señas, se une una dependencia laboral de éstos rayana en situaciones de verdadera servidumbre de la etnia, dado el monopolio que de hecho ostenta la CNSE en su formación y titulación (hasta tiempos muy recientes, pues ya algunas universidades españolas han asumido e iniciado este reto formativo) $y$, sobre todo, contratación, puesto que aquélla y el movimiento asociativo que rígidamente controla absorben, en su casi totalidad, las subvenciones públicas destinadas para estos menesteres.

No obstante unas cifras u otras, lo que si bien es útil para una adecuada planificación financiera y humana de servicios y recursos sociales, no es ello óbice para afirmar la absoluta necesidad de una regulación legal adecuada de esta pluralidad comunicativa, si atendemos al aforismo de que

calcula que, de cada mil nacimientos, nace un niño con sordera congénita, de modo que, si aplicamos esta proporción al total de la población de España, habría, en la actualidad, unas 43.000 personas sordas congénitas. Pero ello no quiere decir que absolutamente todas ellas sean señantes, pues, como señalan varias fuentes de la Confederación Española de Padres y Amigos de los Sordos (FIAPAs), el 96\% de los sordos de nacimiento lo son de padres oyentes, en cuyo entorno familiar la lengua de comunicación es la oral. Cfr. CNse, Memoria de Actividades, folleto informativo correspondiente al ejercicio de 1997, Madrid 1998. Consejería de Servicios Sociales de la Comunidad de Madrid, Censo de las personas con discapacidad en la Comunidad de Madrid, folleto informativo, Madrid I998; Federación de Sordos de la Comunidad de Madrid, Censo electoral, documentación privada, Madrid I998. «el derecho de un hombre es tan sagrado como el de millones de hombres», que sostuviera el iusfilósofo Giorgio del Vecchio ${ }^{15}$, si queremos afirmar de modo efectivo, como quedó apuntado antes, la radical igualdad en la capacidad jurídica de las personas, determinante de una política de plena inclusión social de todas ellas, sin excepciones.

Por supuesto que los sordos, señantes o no, tienen los mismos derechos que los demás ciudadanos, entre ellos el de usar y expresarse libremente en su propia lengua gestual, sin que se les desprecie como «monos» o gestualistas; como también lo tienen todos, en la medida de lo posible y hasta donde la educación recibida se lo permite, a hacerlo en la lengua oral-escrita, sin que se les insulte o menosprecie por ello como «loros» u oralistas, como de hecho se llega a hacer en más de una ocasión, y además dentro de su propia comunidad virtual, resultando impropios ostracismos sociales.

Pues difícilmente nadie puede llegar a conseguir la inclusión e integrarse en el mundo social de modo pleno, si no es capaz de comunicarse en (y con) la sociedad a la que trata de incorporarse, pues la exclusión social supone, con carácter general, la incapacidad de ejercer los derechos sociales, entre otras muchas desventajas. Entre ellas, la marginación del sistema de signos de identificación que constituyen la naturaleza espiritual y cultural de la sociedad, marginación que se presenta notablemente agravada a partir de la expansión creciente de las tecnologías de la información, del procesamiento y difusión de datos y de la comunicación que ${ }^{\mathrm{T} 6}$,

${ }^{15}$ Vid. Gustav Radbruch, «El fin del Derecho», en $I$ d., El hombre en el Derecho, Ed. de Palma, Buenos Aires I980, pp. I03-I20, la cita en p. IO4.

r6 Vid. José Iturmendi Morales, «En torno a la «Comunidad Sorda» ...», op. cit, en José Gabriel Storch de Gracia y Asensio (coord.) \& alii, Estatuto jurídico..., op. cit., ed. cit., pp. I7 y ss. 
a) además de haber producido complejas modificaciones de la esfera pública, de haber conferido a las instituciones jurídicas y políticas un perfil característico y de haber transformado bastantes de las estructuras de las sociedades actuales y no pocos de sus parámetros de referencia,

b) al utilizar un elevadísimo grado de especialización humana y un inmenso caudal de conocimientos y de saber, si bien permiten desarrollar nuevas posibilidades jamás imaginadas por el hombre, al mismo tiempo se diría que «está originando una división del mundo más radical y más distanciadora que la que en su tiempo produjera la primera revolución industrial", como demuestra la distinta velocidad con que las diversas sociedades se están adaptando a los flujos mundializadores ${ }^{17}$.

La accesibilidad a los medios e instrumentos de comunicación (no sólo stricto sensu, sino en el sentido más amplio, incluyéndose entre éstos a la educación en todos sus niveles) ha de favorecer, por supuesto y muy especialmente también a las personas sordas, la aproximación y la familiarización con la sociedad del conocimiento y de la información, así como con lo que constituyen sus instrumentos, nuevas tecnologías de inmensas potencialidades, que abren profundos horizontes a las relaciones de comunicación del hombre con el hombre, así como del hombre con el mundo en el que vive ${ }^{18}$. Al tiempo que a dichas personas sordas les dotan de una enorme

${ }^{17}$ Vid. Juan-Ramón Capella Hernández, «Estado y Derecho ante la mundialización. Aspectos y problemáticas generales», en Íd., (coord.), Transformaciones del Derecho en la mundialización, Consejo General del Poder Judicial, Madrid, I994, pp. 83-I22, la cita en pp. 90-9I.

I8 Vid. Carlos Corrales Díaz, «El significado sociocultural de las nuevas tecnologías de comunicación. Concepciones, usos, funciones, impactos y consecuencias», en Huella. Cuadernos de divulgación académica (Iteso, Guadalajara-Jalisco-México), no ${ }^{\circ} 4$, I987, p. 5; Manuel Martín Serrano, La producción social de comunicación, Alianza Ed., Madrid 1986, pp. 5I-59. -y siempre creciente- capacidad para ampliar las vías de acceso al conocimiento, a la información y a la cultura, a fin de que consigan superar su proverbial desarraigo, alcancen a mejorar su, hoy por hoy, poco envidiable calidad de vida, y logren así participar, de una manera activa y plena, como ciudadanos, no como súbditos subculturales, en la vida política, al igual que en la toma y en la ejecución de las decisiones que les puedan concernir, tanto en el ámbito del Estado al que pertenecen, como en el de las distintas comunidades, reales o virtuales, en las que pudieran encontrarse integradas.

En el análisis que Talcott Parsons realizó acerca de las relaciones entre el sistema social y la organización de la enseñanza primaria en los Estados Unidos de Norteamérica, se identifica una doble función de la educación ${ }^{19}$ :

a) «socialización», es decir, desarrollo en los individuos educandos de los compromisos y actitudes que constituyen los requisitos indispensables del desempeño de su rol futuro como ciudadanos: compromisos en los valores comunes de la sociedad y con el desempeño de un rol especializado, $\mathrm{y}$

b) «selección», esto es, asignación de recursos humanos dentro de la estructura de roles de la sociedad adulta, sin olvidar que la integración social en las sociedades actuales pasa por la formación y por inculcar el sometimiento y respeto a un sistema de valoración y reconocimiento de las diferentes capacidades.

De no hacerse así, está claro que los sordos se contarán $-\mathrm{y}$ de un modo desdichadamente destacado, a la vez que con un horizonte de prolongada permanencia- entre aquellos numero-

I9 Vid. Talcott Parsons, «The School Class as a Social System: Some of Its Functions in American Society», en A. H. Halsey, Jean Floud y C. A. Anderson (ed.), Education, Economy and Society, Free Press, New York 196I, pp. 434-455. 
sísimos grupos sociales «desplazados» a los que se refería Manuel Calvo Hernando cuando, al hablar de los problemas que concluirán por generar en un futuro más o menos inmediato las nuevas tecnologías de la información y de la comunicación, que conocen ritmos crecientes y fugaces de renovación, y de sus proyecciones en la política, la economía, el trabajo, la cultura, la comunicación y las relaciones cívicas, considera que «pondrán en peligro a ciertos grupos sociales $y$ crearán una apocalipsis comunicativa cuyos efectos últimos son, hoy por hoy, impredecibles» ${ }^{20}$.

\section{EL CONTEXTO LEGAL}

\section{I La declaración del derecho de las personas con discapacidad a la accesibilidad en general}

El ámbito de la realidad social en que nos movemos, el de las personas con discapacidad, ha sido regulado fundamentalmente a través de dos normas básicas, que desarrollan lo dispuesto en el art. 49 de la Constitución ${ }^{21}$, puesto en relación con los arts. 9.2 y I4, entre otros, de la propia Carta Magna: La Ley 13/1982, de 7 de abril, de Integración Social de los Minusválidos (LISMI),22 y la Ley 5I/2003, de 2 de diciembre, de Igualdad de Oportunidades, No Discriminación y Accesibilidad Universal de las Personas con Discapacidad (LIONDAU $)^{23}$.

20 Vid. Manuel Calvo Hernando, «Hacia una apocalipsis comunicativa. Los nuevos servicios de la sociedad de la información», en Cuenta y Razón (Fundación de Estudios Sociológicos, Madrid), feb. 1988, núm. XXXIV, pp. 43-46, la cita en la p. 46.

${ }_{21}$ Dicho precepto previene que «los poderes públicos realizarán una política de previsión, tratamiento, rehabilitación e integración de los disminuidos físicos, sensoriales y psíquicos, a los que prestarán la atención especializada que requieran y los ampararán especialmente para el disfrute de los derechos que este Titulo -se refiere al Título I, intitulado «De los derechos y deberes fundamentales»- otorga a todos los ciudadanos».
La primera de dichas leyes, aunque ha sufrido posteriores y varias modificaciones, sigue constituyendo un trabado y, porqué no decirlo, también criticado sistema de reconocimiento de necesidades básicas y de derechos de las personas con discapacidad para desenvolverse adecuadamente en la sociedad, con declaración solemne de las obligaciones del Estado para asegurar la cobertura de los derechos reconocidos. En efecto, y con relación a lo dispuesto en el art. 49 de la norma constitucional, referido a la exigencia del amparo especial que los poderes públicos han de dispensar a los disminuidos para el disfrute de los derechos que la propia Constitución reconoce a todos los ciudadanos, existe una prolija legislación que - directa o indirectamente - podría legitimar la pretensión del establecimiento de las mencionadas técnicas eliminatorias de la inaccesibilidad a la información por parte de las personas sordas:

a) En el ámbito estatal, las leyes, reguladoras de las televisiones y de las telecomunicaciones, al incluir como fines propios de dichos medios de comunicación «el respeto al derecho de libre expresión, al pluralismo social, lingüistico y cultural de todos y al derecho a la igualdad", así como las leyes educativas, de las que es paradigmática la recientísima Ley Orgánica de Educación, cuya Exposición de Motivos declara que «...la educación es el medio de transmitir y, al mismo

${ }_{22}$ El texto original de esta Ley fue publicado en el вOE núm. IO3, de 30 de abril de 1982, texto que luego ha sufrido varias modificaciones.

${ }_{23}$ Cuyo texto fue publicado en el вое núm. 289, de 3 de diciembre de 2003, coincidiendo con el Día Internacional de las Personas con Discapacidad y en el «Año Europeo de las Personas con Discapacidad», declarado así por Decisión del Consejo de la Comunidad (hoy Unión) Europea del 3 de diciembre de 200I, publicada en el Diario Oficial de las Comunidades Europeas (DOCE, hoy Diario Oficial de la Unión Europea o DOUE), Serie L, n 335 , de I9 de diciembre de 2001 . 
tiempo, de renovar la cultura y el acervo de conocimientos y valores que la sustentan, de extraer las máximas posibilidades de sus fuentes de riqueza, de fomentar la convivencia democrática y el respeto a las diferencias individuales, de promover la solidaridad y evitar la discriminación, con el objetivo fundamental de lograr la necesaria cohesión social. Además, la educación es el medio más adecuado para garantizar el ejercicio de la ciudadania democrática, responsable, libre y critica, que resulta indispensable para la constitución de sociedades avanzadas, dinámicas y justas...» ${ }^{24}$. Además, La Ley I3/1982, de 7 de abril, de Integración Social de Minusválidos (LISMI) —con más voluntarismo político, hartas veces incumplido, que efectividad jurídica-, establece en su art. 6, que «...Las medidas tendentes a la promoción educativa, cultural, laboral y social de los minusválidos se llevarán a cabo mediante su integración en las instituciones de carácter general, excepto cuando por las caracteristicas de sus minusvalias requieran una atención peculiar a través de servicios y centros especiales...». $\mathrm{Si}$ consideramos que los servicios de subtitulación textual o de traducción a lenguas señadas son medidas especiales - y necesarias - de promoción social de las personas sordas, respecto del servicio público esencial de televisión —que es, como se reconoce en su legislación específica, instrumento de promoción educativa, cultural y social-, generalmente prestado a través de la conjunción de imagen y sonido por parte de las

\footnotetext{
24 Cfr. el art. IIo.2 de la LOE, a cuyo tenor «...las Administraciones educativas promoverán programas para adecuar las condiciones fisicas, incluido el transporte escolar, y tecnológicas de los centros y los dotarán de los recursos materiales y de acceso al currículo adecuados a las necesidades del alumnado que escolariza, especialmente en el caso de personas con discapacidad, de modo que no se conviertan en factor de discriminación y garanticen una atención inclusiva y universalmente accesible a todos los alumnos». Vid. las pp. web http://www.congreso.es/public_oficiales/L8/CONG/BOCG/A/A_043-I5.PDF.
}

emisoras de televisión, el principio contenido en el art. 6 de la Lismi puede servir de adecuado fundamento legal para exigir el establecimiento generalizado de tales medidas especiales.

b) En el ámbito autonómico, además de las leyes especiales reguladoras de la televisión en los respectivos ámbitos territoriales, igualmente reseñados con anterioridad, son de destacar las leyes promulgadas para la eliminación de barreras de accesibilidad (que la LISMI limita, en el ámbito nacional, a las arquitectónicas y de movilidad), al incluir una regulación de las llamadas «barreras de comunicación», que, por su extensión y falta de uniformidad normativa (auténtica «Torre de Babel» legislativa), no se detalla en este lugar ${ }^{25}$.

Cabe decir aquí, a modo de resumen, que, dentro del ámbito de sus competencias en materia de actuación urbanística, de ordenación de transportes y de asistencia y servicios sociales (asumidas al amparo de lo dispuesto en el art. I48.I. apartados $3^{\circ}, 5^{\circ}$ y $20^{\circ}$, de la Constitución y de sus respectivos Estatutos de Autonomía), las Comunidades Autónomas — además de declarar que su política tenderá a la supresión de barreras arquitectónicas, sensoriales y sociales- han establecido, en la mayor parte de ellas, que se procurará la accesibilidad de todos a los medios de comunicación cuya titularidad o control les corresponda, bien dentro del marco general de eliminación de las barreras arquitectónicas y de

25 Para su detalle, si bien preciso de actualización legislativa, vid. José Gabriel Storch de Gracia y Asensio, "Acerca del derecho...», en Revista Jurídica La Ley, op. cit., pp. I430 y ss., Anexo normativo. Es de señalar la inclusión de las lenguas de señas en el recientísimamente aprobado Estatuto de Autonomía de la Comunidad Valenciana, cuyo art. I3.4 señala que "La Generalitat garantizará el uso de la lengua de signos propia de los sordos, que deberá ser objeto de enseñanza, protección y respeto». Vid. al respecto la $\mathrm{p}$. web http://www.congreso.es/public_oficiales/L8/CORT/BOCG/A/CG_A248.PDF. 
comunicación, entendidas éstas como todo aquel impedimento que limite o menoscabe la emisión o recepción de información. Pero, al igual que ocurre en el ámbito estatal con la LISMI, las declaraciones legislativas autonómicas están, en este punto, más cargadas de voluntarismo político, que de efectividad jurídica obligatoria, remitida en muchos casos a desarrollo reglamentario que no se ha realizado en profundidad.

La LIONDAU, igualmente inspirada, como la anterior LISMI, en las declaraciones internacionales y por transposición de Directivas y Recomendaciones de las instituciones europeas, introduce un nuevo enfoque por el que parecería pretenderse que los derechos reconocidos en la ley anterior sean social y efectivamente ejercidos por las personas con discapacidad (cuyo número en nuestra Patria supera actualmente los tres millones y medio de afectados), mediante el establecimiento de las garantías precisas para la supresión de obstáculos y conductas discriminatorias, la igualación de oportunidades y la plena accesibilidad a los derechos bienes y servicios por parte de un grupo social muy heterogéneo y que se halla en una notoria situación de vulnerabilidad; garantías que permitan actuar frente a la discriminación por el incumplimiento o por actuaciones y actitudes que imposibilitan su ejercicio por las personas con discapacidad ${ }^{26}$.

La citada LIONDAU, inspirada sustancialmente en las técnicas del ADA norteamericano de I990, en muchos casos extrañas a nuestra tradición jurídica continental, establece los principios de no discriminación y, en plazos graduales, la obligación de hacer «ajustes razonables» para eliminar las barreras de accesibilidad en servicios públicos, edificaciones, empresas,

26 Vid. Luis Osorio Gullón, «Presentación» a José Gabriel Storch de Gracia y Asensio (coord.) \& alii, Estatuto jurídico..., op. cit., ed. cit., pp. XXI y ss.. transportes y comunicaciones, inspiradas en el principio de la «acción positiva» como instrumento antidiscriminatorio.

En la materia que nos ocupa, y ante la complejidad de la cuestión (más bien provocada o «inflada» por las maximalistas reivindicaciones de la dirección del movimiento asociativo sordo, que quiere, a toda costa, la declaración de la lengua de señas como «lengua oficial» del Estado español, sin más justificación o razonamiento que desde perspectivas étnico-identitarias, dentro de un discurso victimista $y$, en estos tiempos, "políticamente correcto»), la Ley 5I/2003 pospone la regulación del estatuto jurídico de la lengua de señas del siguiente modo:

Disposición final duodécima. Lengua de signos.

En el plazo de dos años desde la entrada en vigor de esta ley, el Gobierno regulará los efectos que surtirá la lengua de signos española, con el fin de garantizar a las personas sordas y con discapacidad auditiva la posibilidad de su aprendizaje, conocimiento y uso, así como la libertad de elección respecto a los distintos medios utilizables para su comunicación con el entorno.

Tales efectos tendrán una aplicación gradual en los diferentes ámbitos a los que se refiere el artículo 3 de esta ley.

Es de señalar, de entrada, que la autorización al Gobierno contenida en esta Disposición es para «regular», lo que no es posible en materias reservadas a Ley (como las eventuales y necesarias reformas del Código Civil, de leyes procesales o de legislación notarial, por ejemplo), en cuyo caso lo que procede es que el Gobierno eleve el correspondiente Proyecto de Ley a las Cortes, como efectivamente así ha sucedido.

Posteriormente y en el mes de noviembre de 2004, se nos ha solicitado, por parte de varios órganos de la Administración General del Estado, además de un informe razonado sobre un 
Borrador de Proyecto de Ley presentado por la CNSE, un texto alternativo a dicho Borrador, que se envió para ser sometido a estudio y valoración ${ }^{27}$.

Tras las pertinentes reuniones y sesiones de trabajo en el Ministerio de Trabajo y Asuntos Sociales - a varias de las cuales se invitó, en atención al principio de «transversalidad» reconocido en la Ley $5^{\mathrm{I}} / 2003$, a las principales entidades representativas de las personas con discapacidad y de sus familias (concretamente, al cermi o Comité Español de Representantes de Personas con Discapacidad, del que forman parte como miembros tanto la Confederación Nacional de Sordos de España - CNSE-, y la Confederación Española de Padres y Amigos de los Sordos - riapas-), el Gobierno de la Nación aprobó en Consejo de Ministros, celebrado el I6 de septiembre de 2005, el Anteproyecto de Ley por el que se reconoce la Lengua de Signos y se regula el derecho a su aprendizaje, conocimiento y uso, y se establecen y garantizan los Medios de Apoyo a la Comunicación Oral de las Personas Sordas, con Discapacidad Auditiva y Sordociegas, datado en Madrid, el día I4 de septiembre de 2005, remitiéndolo a informe del Consejo de Estado con carácter previo a su tramitación parlamentaria ${ }^{28}$.

27 Para su detalle, vid. José Gabriel Storch de Gracia y Asensio (coord.) \& alii, Estatuto jurídico..., op. cit., ed. cit., pp. 479-49r y José-Gabriel Storch de Gracia y Asensio:»Derecho a la información y discapacidad (una reflexión acerca del lenguaje de los sordos)», op. cit., passim.

${ }_{28}$ De acuerdo con lo establecido en el art. 22 de la Ley 50/1997, de 27 de noviembre, del Gobierno (вов 28II-I997, Modificada por la Ley 30/2003, de I3 de octubre. воE I4-IO-2003). Las versiones de este Anteproyecto pueden consultarse en las pp. web http://www.cermi.es/NR/ rdonlyres/7IF353BI-DDB9-42I7-A2C8-99F4D7876EBD/3336/ PROYECTOLEYLENGUADESIGNOSYMACOI3OIO6.doc (con fecha de 28 de diciembre de 2005) y en http://www.farocnse. $\mathrm{com} /$ documentos/Ley.doc (datado el I4 de septiembre de 2005).
El Consejo de Estado emitió su Dictamen núm. $1579 / 2005$, de 24 de noviembre, favorable a la tramitación legislativa, si bien con las observaciones que aporta ${ }^{29}$.

El Gobierno de la Nación, atendiendo algunas de las sugerencias formuladas en el Dictamen emitido por el Consejo de Estado, aprobó, en Consejo de Ministros de fecha de I3 de enero de 2006, el Proyecto de Ley ${ }^{3 \circ}$, que tuvo entrada en el Congreso de los Diputados el I6 de enero de 2006, estando actualmente en fase de tramitación parlamentaria ante dicha Cámara legislativa.

Aunque este Proyecto aún carece de eficacia jurídica, su importancia radica en que constituye, como muy bien señala el Consejo de Estado en su Dictamen, un punto de partida - programa legislativo para un posterior desarrollo reglamentario- de los efectos jurídicos que llegará a tener el uso y aprendizaje de la lengua de señas y de los medios de apoyo a la comunicación oral para las personas con deficiencias o limitaciones auditivas ${ }^{3}$.

29 Cfr. la p. web http://www.boe.es/g/es/bases_datos_ce/doc.php? coleccion $=$ ce $\&$ id $=2005-1579$.

$3^{\circ}$ Cfr. las pp. web. http://www.la-moncloa.es/consejodeministros/referencias/_2006/referencia+consejo+I3OIO 6.htm y http://www.congreso.es/public_oficiales/L8/coNG/ BOCG/A/A_O73-OI.PDF.

${ }^{3} \quad$ El propio Consejo de Estado recomienda en su Dictamen la simplificación y no reiteración de las denominaciones que sobre el objeto y los destinatarios de la futura ley se contienen repetitivamente en el Anteproyecto informado, opinión que suscribimos. En parecido sentido se pronuncia Alfredo Romero Gallardo, «Breve comentario sobre el Anteproyecto de Ley de la Lengua de Signos Española y de Apoyo a la Comunicación Oral para las Personas Sordas o con Discapacidad Auditiva y Sordociegas", en Boletín Jurídico Derecho.com, Enero 2006, sub nota I4, accesible en la p. web http://libros.derecho.com/boletin/articulos/articulor7.htm. Para un mayor detalle del contenido del proyecto de ley, vid. el trabajo citado en último lugar y José-Gabriel Storch de Gracia y Asensio: «Derecho a la información y discapacidad (una reflexión acerca del lenguaje de los sordos)», op. cit., passim. 


\subsection{La declaración del derecho a recibir información a través de la televisión}

Concretando, pues, y por las razones antedichas, el ámbito de este estudio a la medida de la exigibilidad del derecho a recibir información a través del medio televisivo, hemos de afirmar que tal derecho está consagrado constitucionalmente como uno de los medios básicos para el ejercicio de los derechos fundamentales conformadores de la estructura pluralista y democrática de la Sociedad, pues, como dice, harto reiteradamente, el Tribunal Constitucional, «... Respecto a la consideración de la televisión como servicio público, no debe olvidarse que el art. $20 \mathrm{CE}$, además de los derechos subjetivos de expresión e información, garantiza el derecho de todos a recibir información y tiene una misión de garantia de una institución fundamental cual es la opinión pública libre, que transciende a lo que es común y propio de otros derechos fundamentales (S I04/I986, FJ 5. $\left.{ }^{\circ}\right)$... la comunicación pública libre no sólo exige la garantía del derecho de todos los ciudadanos a la expresión del pensamiento y a la información, sino también la preservación de un determinado modo de producirse de los medios de comunicación social, porque tanto se viola la comunicación libre al ponerle obstáculos desde el poder, como al ponerle obstáculos desde los propios medios de difusión (STC I2/I982, FJ 6. ${ }^{\circ}$ )... y por lo que respecta a la televisión, el legislador ba querido que su modo de producción sea en forma de servicio público también, y asi se dice en la $E$. de M. L 4/I980 de Io Ene. (Estatuto de Radiodifusión y Televisión), porque también la televisión es un vehiculo esencial de información y participación politica de los ciudadanos, de formación de la opinión pública, de cooperación con el sistema educativo, de difusión de cultura española y de sus nacionalidades y regiones, asi como medio capital para contribuir a que la libertad y la igualdad sean reales y efectivas... ${ }^{32}$.
Haciéndose omisión, aquí, del tratamiento del derecho (empresarial) al libre establecimiento de medios de comunicación social televisivos -al que se refieren las Sentencias mencionadas 127 y que guarda relación, no sólo con el derecho a la libertad de expresión, sino también al de libertad de establecimiento mercantil, ex arts. 33 y 38 de la Constitución, con las limitaciones y requisitos establecidos en las leyes reguladoras de dichos medios-, es claro que, a la luz de la doctrina constitucional transcrita, tal libertad de establecimiento tiene su contrapunto en la exigencia de pluralismo y de veracidad en la información que se difunde, a fin de afirmarse, de este preciso modo, la plena existencia de una opinión pública verdaderamente libre, de la que es - o debe ser- beneficiaria, la sociedad entera y todos y cada uno de sus integrantes, sin exclusiones.

Pero resulta que, por vía de hecho, las personas sordas tienen dificultado o impedido —así, pues, limitado o menoscabado, en mayor o menor medida, según la intensidad de la sordera- su derecho a recibir información, cuando ésta se instrumenta mediante el sonido: conversación oral, Radio y Televisión.

La doctrina constitucional, recogida en las Sentencias citadas en último lugar, señala que la legitimidad constitucional de la calificación de la televisión como servicio público responde a una serie de razones, entre las que se cuentan las de carácter técnico, que no son, sin embargo, las únicas que pueden justificar este tipo de configuración del medio. Así, la calificación

${ }^{22}$ Cfr STC, Sala $2^{\mathrm{a}}$, no $206 /$ r.99o, del I7 de diciembre, Ponente Excmo. Sr. Rodríguez-Piñeiro Bravo-Ferrer. Las citadas, son, respectivamente, las Sentencias del Pleno del Tribunal Constitucional, números 106/r.986, del 24 de julio (Ponente Excmo. Sr. Truyol y Serra) y I2/r.982, del 3I de marzo (Ponente Excmo. Sr. Díez-Picazo y Ponce de León). 
de servicio público es constitucionalmente legítima desde el momento en que el legislador la considera necesaria para garantizar -en 128 términos de igualdad y efectividad - determinados derechos fundamentales de la colectividad, pero no es, en absoluto, una etiqueta que una vez colocada sobre el medio, permita cualquier regulación de la misma, ya que hay en juego derechos subjetivos - los de comunicar (y recibir) libre y verazmente el pensamiento y la información - que la publicación limita y sacrifica en favor de otros derechos, pero que no puede en modo alguno eliminar.

El Tribunal Constitucional, en más de una ocasión, ha señalado alguna de las condiciones que hacen constitucionalmente legítima la regulación de esta actividad (televisiva) como servicio público. Así, refiriéndose en general a los medios de comunicación, dice el Tribunal Constitucional que «para que se produzcan dentro del orden constitucional tienen ellos mismos que preservar el pluralismo» y por lo que respecta a la televisión privada, que «su implantación era una decisión política que podía adoptarse siempre que, al organizarla, se respeten los principios de libertad, igualdad y pluralismo, como valores fundamentales del Estado»33.

En este sentido, el Tribunal Europeo de Derechos Humanos ha declarado que «si bien es verdad que los Estados miembros gozan de un cierto margen de apreciación para decidir sobre la existencia y la extensión de las injerencias en la libertad de expresión (art. Io.I del Convenio Europeo de Derechos Humanos), no lo es menos que corresponde a ese Tribunal juzgar si las medidas en que se concreta esa

33 Cfr. la STC $12 / 1982$, del 3r de marzo (Ponente Excmo. Sr. Díez-Picazo y Ponce de León), Fundamento Jurídico $6 .^{\circ}$. injerencia se justifican y son proporcionadas, de acuerdo con los límites expresados en el párr. 2 del precepto citado, o sea, restricciones previstas por la Ley, que constituyan medidas necesarias, en una sociedad democrática, para los fines que indica.... ${ }^{34}$.

En España, la televisión, al igual que la radio, está declarada servicio público esencial y su gestión está regulada en forma mixta, es decir, pública - por el Estado y las Comunidades Autónomas- y privada, por las sociedades privadas que han obtenido la pertinente concesión para ello35.

El art. I $^{\circ}, 2$ de la Ley $4 /$ r98o, de ro de enero, consagra el principio de que la radiodifusión y la radiotelevisión son «servicios públicos esenciales» cuya titularidad corresponde al Estado. La consideración de la televisión como un servicio público esencial la fundamenta paladinamente en el preámbulo de dicha ley en que «... tanto la televisión como la radiodifusión son un vehículo esencial de información y de participación política de los ciudadanos, de formación de la opinión pública, de cooperación con el sistema educativo, de difusión de la cultura española y de sus nacionalidades y regiones y de medio de contribución para que la libertad y la igualdad sean efectivas...». Todo ello permite afirmar, como hace el Tribunal Constitucional, que la configuración de la televisión como servicio público, aunque no

\footnotetext{
34 Cfr. stedh del 28 de marzo de 1.990 , $n^{\circ}{ }_{14} / \mathrm{I} .988 / \mathrm{I}_{5} 8 / 2 \mathrm{I} 4$.

35 Cfr. los arts. I.2 de la Ley 4/198o, Reguladora del Estatuto Orgánico del Ente Público de Radio y Televisión, 2.I de la Ley 31/1987, del I8 de diciembre, de Ordenación de las Telecomunicaciones, I de la Ley ro/1988, reguladora de la Televisión Privada, y 2 de la Ley 4I/r995, del 22 de diciembre, reguladora de la Televisión Local por Ondas. Sobre la gestión, cfr. las Leyes, del 3 de mayo, Io/I988, reguladora de la Televisión Privada y 47/1983, del Tercer Canal.
} 
sea una afirmación necesaria en nuestro orden jurídico-político, se encuentra dentro de los poderes del legislador.

Servicio público esencial que, en nuestro sistema jurídico, se inspira en unos principios de orden constitucional, cuyo alcance quedó expresado en la doctrina del Tribunal Constitucional anteriormente extractada.

En el ámbito de la Televisión de titularidad pública, el art. $4^{\mathrm{o}}$ de la Ley $4 /$ I980, de ro de enero, Reguladora del Estatuto de la Radio y la Televisión, dice lo siguiente:

«La actividad de los medios de comunicación social del Estado se inspirará en los siguientes principios:

a) La objetividad, veracidad e imparcialidad de las informaciones.

b) La separación entre informaciones y opiniones, la identificación de quienes sustentan estas últimas y su libre expresión, con los límites del apartado 4 del artículo 20 de la Constitución.

c) El respeto al pluralismo político, religioso, social, cultural y lingüístico.

d) El respeto al honor, la fama, la vida privada de las personas y cuantos derechos y libertades reconoce la Constitución.

e) La protección de la juventud y de la infancia.

f) El respeto de los valores de igualdad recogidos en el artículo I4 de la Constitución».

En idéntico sentido y con relación a la Televisión privada, el art. 3 de la Ley Io/ı988, de 3 de mayo, reguladora de su estatuto jurídico, establece que «... La gestión indirecta por parte de las Sociedades concesionarias se inspirará en los principios expresados en el artículo $4^{\circ}$ de la Ley 4/1980, de ro de enero, de Estatuto de la Radio y la Televisión...» ${ }^{36}$.

36 Cuyo incumplimiento, imputable a las sociedades concesionarias, será considerado como falta muy grave (ex art.
El cumplimiento de todos estos fines justifica la calificación legislativa de que la televisión —ora sea de gestión directa o pública, ya de gestión indirecta o privada- sea un servicio público esencial. $\mathrm{O}$, como dice la Exposición de Motivos de la Ley ro/r988, de 3 de mayo, reguladora de la Televisión Privada, «... La finalidad de la televisión como tal servicio público ba de ser, ante todo, la de satisfacer el interés de los ciudadanos y la de contribuir al pluralismo informativo, a la formación de una opinión pública libre y a la extensión de la cultura ...».

Entendido, con carácter general y con las oportunas salvedades doctrinales, un servicio público como « ...aquella actividad constituida por el Poder Público para satisfacer necesidades colectivas, prestada por la Administración - directa o indirectamente- con carácter general y continuo y sometida a un régimen jurídico especial .... ${ }^{37}$, es de notar que una de sus características es la de generalidad o universalidad, esto es, que los servicios públicos se constituyen para proporcionar utilidad a todos los ciudadanos interesados.

Pero es que, además, tanto por la Constitución como por las Leyes especiales antes reseñadas, se califica a la Televisión como servicio público esencial, entendida esta esencialidad como característica sin la cual no pueden entenderse correctamente ejercitables ciertos derechos fundamentales.

Tanto más esencial para las personas sordas, cuanto que éstas sólo pueden recibir informa-

2I.2 de la misma Ley ro/I988), con el efecto de poder rescindirse la concesión de la gestión indirecta del correspondiente canal de televisión privada o de no renovarse dicha concesión.

37 Vid., con carácter general, Gascón y Marín, Tratado de Derecho Administrativo, I, $7^{\mathrm{a}}$ ed., págs. 216 y 217, o Garrido Falla, Tratado de Derecho Administrativo, II, $5^{\text {a }}$ ed., Madrid I.975, págs. 346 y ss. 
ción a través de las imágenes y del texto, no del sonido. De manera que si no se hace accesible la Televisión a aquéllas, mediante la adecuada subtitulación de sus programas -especialmente los de contenido informativo-, se incumple el principio de la generalidad del servicio público de televisión y, lo que es más grave aún, se les cercenan o limitan aquellos derechos fundamentales que son ejercitables a través de dicho medio de comunicación.

\subsection{La exigibilidad del derecho a recibir información a través de la televisión}

Por todo lo antedicho, el derecho a una televisión accesible - como presupuesto indispensable para el ejercicio por parte de las personas sordas de otros derechos fundamentales reconocidos en el Capítulo Segundo del Libro Primero de la Constitución - vincula a todos los poderes públicos, y así se establece explícitamente en el art. 53.I de la Constitución, con la consecuencia de que las leyes que han de regular el ejercicio de los derechos fundamentales allí reconocidos han de respetar, en todo caso, su contenido esencial (así, por ejemplo, para el derecho al acceso a la cultura, ex art. 44.I de la Constitución, en conexión con la finalidad de divulgación cultural, además de meramente informativa, de la televisión, así reconocida en su legislación especial, en los términos antedichos).

Pero no sólo eso: una televisión inaccesible, por afectar al ejercicio de derechos fundamentales reconocidos en el artículo I4 (derecho a la igualdad) y en la Sección Primera del Capítulo Segundo del Título Primero de la Constitución (derecho a la libre expresión, ex art. 20, y derecho a la educación, ex art. 27), plantea la razonable consecuencia de que el derecho a la televisión accesible por parte de las personas sordas pueda ser directa e incondicionalmente exigible por éstas ante las Empresas titulares de la gestión de las correspondientes cadenas de televisión, ante las Autoridades administrativas competentes y, en su caso, ante los Tribunales ordinarios, terminando dicha reclamación, eventualmente, con el correspondiente recurso constitucional de amparo, ex arts. 53.2 y i6r.r.b) de la Constitución o con una demanda ante el Tribunal Europeo de Derechos Humanos. En casos de menor entidad así se ha reconocido.

Esta reclamación directa y jurídicamente incondicionada puede concretarse, por ahora $y$ sin excluir otros medios que el continuo avance de la Técnica pueda ofrecer en el futuro, en el establecimiento, simultáneo a la emisión de los programas informativos (entendidos éstos, en la línea de la jurisprudencia constitucional, como aquéllos que sean conformadores de opinión pública libre, tales como noticiarios o telediarios, avances informativos, programas de debates políticos y/o sociales, revistas informativas, espacios electorales, etc.), de los siguientes medios de traducción de las informaciones emitidas por medio sonoro:

a) En todo caso, mediante la subtitulación textual en las lenguas orales (oficiales) vigentes $^{3^{8}}$.

b) De modo eventual, por ahora, a través de la traducción a la lengua gestual correspondiente ${ }^{39}$.

$3^{8} \quad \mathrm{O}$ audiodescripción para las personas ciegas. Sobre subtitulación textual de los programas de televisión, vid. López de Zuazo y Algar, Subtitulado por TXT y páginas para personas sordas en España, Comunicación presentada en el I Simposio sobre Eliminación de las Barreras de Comunicación, La Coruña, 2I-23 de noviembre de 1997 y la bibliografía que allí se recoge. Sobre subtitulación y audiodescripción, cfr, además, las referencias citadas en Orero, Pereira y Utray, «Visión histórica de la accesibilidad en los medios en España», en otro lugar de este mismo volumen.

39 En España conviven dos lenguas gestuales distintas, utilizadas por las personas sordas: la Lengua de Señas Espanola, de uso general en todo el territorio nacional -aunque 
Y ante la más que probable objeción - generalmente fundadas en razones de índole presupuestaria, o amparadas en lo dispuesto en el apartado 3 del art. 53 de la Constitución, por el que el reconocimiento, el respeto y la protección de los principios reconocidos en el Capítulo Tercero del Título Primero de dicha Constitución sólo podrán ser alegados ante la jurisdicción ordinaria de acuerdo con lo que se disponga en las leyes que los desarrollen, pues podríamos hallarnos ante un «derecho fundamental de prestación» más que ante una «libertad fundamental», en el sentido apuntado, reiteradísimamente, por la doctrina del Tribunal Constitucional-, se ha de señalar que, por el momento y a la vista del estado actual de la legislación española, el derecho a una televisión accesible es defectuosamente exigible de manera inmediata e incondicionada si se funda solamente en razones de legalidad ordinaria.

En efecto, y con relación a lo dispuesto en el art. 49 de la norma constitucional, referido a la exigencia del amparo especial que los poderes públicos han de dispensar a los disminuidos para el disfrute de los derechos que la propia Constitución reconoce a todos los ciudadanos, existe una prolija legislación que - directa o indirectamente- podría legitimar la pretensión

con variantes dialectales de ámbito local o regional de las señas utilizadas-, y la Llengua de Senyes Catalana, utilizada básicamente y con carácter mayoritario en la comunidad catalana. Se echa en falta, en España y en español, la existencia de estudios rigurosos y profundos - tanto desde el punto de vista antropológico-cultural, como desde la perspectiva lingüística-, sobre dichas lenguas gestuales y sobre las comunidades que las utilizan; ello puede ser debido, fundamentalmente, a la ignorancia o desconocimiento prestado por parte de la mayoría de la comunidad académica oficial (conformada en su integridad por personas oyentes) a dichas cuestiones y que constituyen terreno casi «virgen» para la elaboración de estudios o tesis doctorales. Desde aquí animamos a los interesados a tratar sobre ello. del establecimiento de las mencionadas técnicas eliminatorias de la inaccesibilidad de la televisión para las personas sordas:

a) En el ámbito estatal, las leyes, ya citadas, reguladoras de las televisiones y de las telecomunicaciones, al incluir como fines propios de dichos medios de comunicación el respeto al derecho de libre expresión, al pluralismo social, lingüístico y cultural de todos y al derecho a la igualdad, en los términos expuestos antes. Además, La Ley I3/1982, de 7 de abril, de Integración Social de Minusválidos (LISMI) —con más voluntarismo político, hartas veces incumplido, que efectividad jurídica-, establece en su art. $6^{\circ}$, que «...Las medidas tendentes a la promoción educativa, cultural, laboral y social de los minusválidos se llevarán a cabo mediante su integración en las instituciones de carácter general, excepto cuando por las características de sus minusvalias requieran una atención peculiar a través de servicios y centros especiales...». Si consideramos que los servicios de subtitulación textual o de traducción a lenguas señadas son medidas especiales -y necesarias - de promoción social de las personas sordas, respecto del servicio público esencial de televisión - que es, como se reconoce en su legislación específica, instrumento de promoción educativa, cultural y social-, generalmente prestado a través de la conjunción de imagen y sonido por parte de las emisoras de televisión, el principio contenido en el art. $6^{\circ}$ de la LISMI puede servir de adecuado fundamento legal para exigir el establecimiento generalizado de tales medidas especiales.

b) En el ámbito autonómico, además de las leyes especiales reguladoras de la televisión en los respectivos ámbitos territoriales, igualmente reseñados con anterioridad, son de destacar las leyes promulgadas para la eliminación de barreras de accesibilidad (que la LISMI limita, en el ámbito nacional, a las arquitectónicas y de movilidad), al 
incluir una regulación de las llamadas «barreras de comunicación», que, por su extensión y falta de uniformidad normativa (auténtica «Torre de Babel» legislativa), se extracta en anexo.

Cabe decir aquí, a modo de resumen, que, dentro del ámbito de sus competencias en materia de actuación urbanística, de ordenación de transportes y de asistencia y servicios sociales, - asumidas al amparo de lo dispuesto en el art. I48.I. apartados $3^{\circ}, 5^{\circ}$ y $20^{\circ}$, de la Constitución y de sus respectivos Estatutos de Autonomía-, las Comunidades Autónomas —además de declarar que su política tenderá a la supresión de barreras arquitectónicas, sensoriales y sociales- han establecido, en la mayor parte de ellas, que se procurará la accesibilidad de todos a los medios de comunicación cuya titularidad o control les corresponda, bien dentro del marco general de eliminación de las barreras arquitectónicas y de comunicación, entendidas éstas como todo aquel impedimento que limite o impida la emisión o recepción de información, ya mediante el establecimiento expreso - pero de implantación gradual- de las técnicas de subtitulación textual o de la traducción a lenguas de signos gestuales. Pero, al igual que ocurre en el ámbito estatal con la LisMi, las declaraciones legislativas autonómicas están, en este punto, más cargadas de voluntarismo político, que de efectividad jurídica obligatoria, remitida en muchos casos a desarrollo reglamentario que no se ha realizado en profundidad.

\section{CONCLUSIÓN}

En conclusión, la exigibilidad del derecho de acceso a la televisión por parte de las personas con discapacidad auditiva, si se fundamenta en la legislación ordinaria, dependerá del grado de implantación en dicho medio de comunicación de las ayudas técnicas de subtitulación o de traducción a lenguas de señas, dependiente a su vez de coyunturales posibilidades presupuestarias y de precarias voluntades políticas ${ }^{4}$.

Ya dijimos en 1998 que, entonces — sin perjuicio de la presión cotidiana que han de continuar ejerciendo las asociaciones representativas de las personas sordas ante las instancias políticas y administrativas competentes-, para que se pueda hacer valer la efectividad del derecho de acceso a los medios de comunicación por parte de los discapacitados auditivos, podría plantearse la necesidad de iniciar, administrativa y procesalmente, una línea de actuación reivindicativa que - con fundamento en los principios constitucionales antes expuestostermine en una eventual declaración favorable por parte del Tribunal Constitucional español o del Tribunal Europeo de Derechos Humanos. Sólo así se podría obligar al legislador —estatal o autonómico- a que imponga a los gestores de los medios de comunicación «visuales» (la raíz significante «audio» queda aquí, deliberadamente, suprimida, por inaccesible) el deber incondicionado de hacer accesible dichos medios a todos, sin exclusiones ni discriminaciones de ningún tipo, de forma explícitamente imperativa y por medio de las correspondientes leyes (sustituyéndose, por ejemplo, el socorrido término "procurarán gradualmente» por el de «deberán», en el plazo prudencial que expresamente se fije, con establecimiento expreso y claro de régimen sancionador para caso de incumplimiento).

40 Así, a título de iniciativa, fue desde el ro de marzo de 1998, cuando se ha establecido en el ámbito de la Comunidad Autónoma de Cantabria un servicio de traducción a lengua de señas del informativo autonómico de las 20 'oo horas, en el Canal I de la Televisión Española (Fuente: Páginas 800 y siguientes del Teletexto de dicho Canal televisivo). Pero es que los demás informativos siguen siendo inaccesibles, condicionándose la vida autónoma de las personas sordas a los horarios accesibles, no a la posibilidad de elección que tienen las personas oyentes. 
En el entretanto, la citada LIONDAU de 2003 ha venido a concretar aún más la efectividad del derecho, sólo que falta aún de la eficacia que pudiera tener, por la ausencia de normas sancionadoras que, coactivamente, sancionen el incumplimiento del deber general de accesibilidad. Normas sancionadoras que, por fin, parece que tendrán expresión cuando se apruebe el actual Proyecto de Ley por la que se establece el régimen de infracciones y sanciones en materia de igualdad de oportunidades, no discriminación $y$ accesibilidad universal de las personas con discapacidad (LISIONDAU), actualmente en fase de tramitación parlamentaria ante el Congreso de los Diputados ${ }^{4 \mathrm{I}}$.

Así pues, y hasta que no se concrete dicha legislación sancionadora, vale, aún y en esencia, lo dicho en 1998.

RECIBIDO EN DICIEMBRE 2006 ACEPTADO EN ENERO 2007

\section{BIBLIOGRAFÍA}

Manuel Aznar López (2005), «La lengua de señas en el contexto de los derechos de las personas con discapacidad: Los textos internacionales y la Constitución española», en José Gabriel Storch de Gracia y Asensio (coord.) \& alii, Estatuto jurídico de las lenguas de señas en el Derecho espa-

4I Cfr. la pág. web http://www.congreso.es/public_oficiales/L8/cONG/BOCG/A/A_O74-OI.PDF. En la tramitación parlamentaria del proyecto de ley LLss-MAco se ha propuesto alguna enmienda en el sentido de establecer una legislación de infracciones y sanciones específica para el desarrollo y cumplimiento de esta última Ley. Otra cuestión que queda en el aire es la de determinar la efectividad del régimen sancionador cuando, como ocurre con mucha frecuencia, son los poderes públicos los incumplidores del deber general de accesibilidad universal y diseño para todos: ¿se autosancionará?; esto, más que dudoso, es jurídicamente insostenible. ñol (Aproximaciones), Col. Por más señas, Ed. Universitaria Ramón Areces, Madrid 2005, pp. 275-294 y 295-4I4, respectivamente.

Manuel Calvo Hernando (I988), «Hacia una apocalipsis comunicativa. Los nuevos servicios de la sociedad de la información», en Cuenta y Razón (Fundación de Estudios Sociológicos, Madrid), feb. I988, núm. xxxiv, pp. 43-46

Juan-Ramón Capella Hernández (I994), «Estado y Derecho ante la mundialización. Aspectos y problemáticas generales», en $I$ d., (coord.), Transformaciones del Derecho en la mundialización, Consejo General del Poder Judicial, Madrid, I994, pp. 83-I22.

CNSE (1997), Memoria de Actividades, folleto informativo correspondiente al ejercicio de 1997, Madrid I998.

Consejería de Servicios Sociales de la Comunidad De Madrid (1998), Censo de las personas con discapacidad en la Comunidad de Madrid, folleto informativo, Madrid 1998.

Carlos Corrales Díaz (1987), «El significado sociocultural de las nuevas tecnologías de comunicación. Concepciones, usos, funciones, impactos y consecuencias», en Huella. Cuadernos de divulgación académica (Iteso, Guadalajara-Jalisco-México), $\mathrm{n}^{\mathrm{o}}{ }_{14}, \mathrm{I} 987$, p. 5.

Federación de Sordos de la Comunidad de Madrid (I998), Censo electoral, documentación privada, Madrid i998.

Antonio Gascón Ricao (1998-2003): ¿ Señas o signos?: Evolución histórica, en la p. web www.ucm.es/ info/civil/bardecom/docs/signos.pdf.

Antonio Gascón Ricao y José Gabriel Storch De Gracia Y Asensio (2003): Historia de la Lengua de Señas Española: Polémicas, tópicos, mitos y leyendas, en la p. web www.ucm.es/info/civil/herpan/docs/ historiai.pdf.

Antonio Gascón Ricao y José Gabriel Storch De Gracia Y Asensio (2004), Historia de la educación de los sordos en España y su influencia en Europa y América, Ed. Universitaria Ramón Areces, Col. Por Más Señas, Madrid 2004.

José Iturmendi Morales (2005), «En torno a la «Comunidad Sorda» como comunidad de aprendizaje y de actitudes de pertenencia y de fidelidad. Una aportación al debate entre comunitaristas y liberales acerca de los derechos, los valores y la Sociedad», en José Gabriel Storch de Gracia y 
Asensio (coord.) \& alii, Estatuto juridico..., op. cit., ed. cit., passim.

Manuel López Torrijo (2005), La educación de las personas con sordera: La escuela oralista española, Universitat de València, Valencia 2005.

Manuel Martín Serrano (1986), La producción social de comunicación, Alianza Ed., Madrid I986, pp. 51-59.

Luis Osorio Gullón (2005), «Presentación» a José Gabriel Storch de Gracia y Asensio (coord.) \& alii, Estatuto jurídico..., op. cit., ed. cit., pp. XXI y ss.

Talcott Parsons (I96I), «The School Class as a Social System: Some of Its Functions in American Society», en A. H. Halsey, Jean Floud y C. A. Anderson (ed.), Education, Economy and Society, Free Press, New York I96I, pp. 434-455.

Gustav Radbruch (I980), «El fin del Derecho», en Íd., El hombre en el Derecho, Ed. de Palma, Buenos Aires I980, pp. I03-I20.

Alfredo Romero Gallardo (2006), «Breve comentario sobre el Anteproyecto de Ley de la Lengua de Signos Española y de Apoyo a la Comunicación Oral para las Personas Sordas o con Discapacidad Auditiva y Sordociegas», en Boletín Jurídico Derecho.com, Enero 2006, sub nota I4, accesible en la p. web http://libros.derecho.com/boletin/ articulos/articulor7.htm.

Giovanni Sartori (200o), Homo videns. La sociedad teledirigida, Col. Taurus Pensamiento, Ed. Taurus, $2^{\mathrm{a}}$ ed. anotada, Madrid 2000, pp. I27 y ss.
Giovanni Sartori (200I), La sociedad multiétnica, Pluralismo, multiculturalismo y extranjeros, Col. Taurus Pensamiento, Ed. Taurus, Madrid 200I, pp. I05-I26.

José Gabriel Storch De Gracia Y Asensio, (1998a): El nombre de nuestra lengua, en la p. web http://www. ucm.es/info/civil/bardecom/docs/signa.pdf.

José-Gabriel Storch De Gracia Y Asensio (I998b): "Acerca del derecho de las personas sordas a una televisión accesible», en Revista Jurídica La Ley, I998, vol. 4, pp. I430 y ss.

José Gabriel Storch De Gracia Y Asensio (2005), «Derecho comparado: Las lenguas de señas en los textos extranjeros (Recopilación legislativa)», en José Gabriel Storch De Gracia Y Asensio (coord.) \& alii, Estatuto jurídico de las lenguas de señas en el Derecho español (Aproximaciones), Col. Por más señas, Ed. Universitaria Ramón Areces, Madrid 2005, pp. 275-294 y 295-4I4, respectivamente.

José-Gabriel Storch De Gracia Y Asensio (2006): «Derecho a la información y discapacidad (una reflexión acerca del lenguaje de los sordos)», en Revista General de Información y Documentación (Madrid: 2006), vol. I6, nº I, págs. 75-103.

Ludwig Wittgenstein (1973), «Tractatus logico-philosophicus», trad. cast. de Enrique Tierno Galván, Alianza Ed., Madrid, I973, p. I63. 